\title{
APPLICATIONS OF THE POLYMERIC TEMPLATES
}

\author{
Prof. Ruxandra Vidu \\ University of California Davis, One shields Avenue, CA 95616 \\ Email: rvidu@ucdavis.edu \\ Director, UE Project University Politehnica of Bucharest, Faculty of Materials \\ Science and Engineering
}

\begin{abstract}
In recent years, there has been considerable interest in synthesis of nanostructured materials. Special attention has been given to the control of particle shape and geometry. The main types of such nanostructured systems are nanoparticles, nanotubes, nanofibers and nanocables. Nanoparticles are attractive building blocks for material architectures and can be prepared from a variety of materials. On the other hand, template synthesis has been proven to be a versatile approach for preparing nanostructures, such as nanotubes, nanofibers and nanocables, with various aspect ratios. The trend toward miniaturization and the high output of integrated circuits have stimulated the development of nanostructured materials and new synthesis methods. This paper reviews the general approach for using nanoporous polymeric membrane for molecular separation and mass transfer.
\end{abstract}

\section{Polymeric Templates for Separation and Mass Transfer Gates}

Polymeric nanoporous membranes are excellent templates for growing multiscale nanostructures inside nanopores. Nanoporous membranes can be used for molecular separations [1-10], biosensing [11] and catalytic applications [12]. Moreover, PCTE membranes can be assembled with microfluidic devices as molecular gates $[13,14]$. In this section, we will discuss the use of surface-modified, nanoporous membranes for molecular separation and mass transfer gates. Zydney et al. [15] have described some of the fundamental colloidal interactions that govern molecular transport through porous membranes.

\section{Principle}

Ultrafiltration has been used for molecular separation. Ultrafiltration is a traditional, sizebased separation process. When the size of the pores in a membrane approaches the size of the molecules, the separation can be efficient and high purification is possible. Size-based separation for nanoporous membranes is shown in Fig. 1.

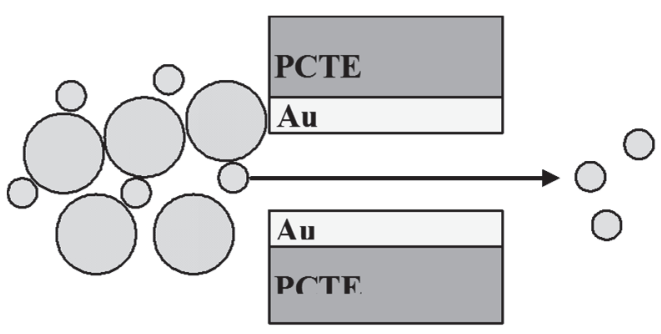

Fig. 1. Sized-based separation in nano-porous membrane.

Martin et al. [9] have demonstrated sizebased separation in polymeric nanoporous membranes. The polymeric membrane used was a PCTE membrane with a narrow pore size distribution. When a mixture of "smaller" and "larger" molecules attempt to pass through a nanoporous membrane, the larger molecules are not detectable at the other side if the nanopore diameter is equal or smaller than the characteristic dimension of the larger molecules. For larger pore sizes, separation of smaller from larger molecules is still possible because the larger molecules will experience a significantly larger wall hindrance than the smaller molecules. From single molecule 
transport, the selectivity coefficient of pyridine/quinine can be over 15,000 by using nanoporous membrane. The pore size of the starting polymeric membrane was $30 \mathrm{~nm}$ in diameter. The pore size can be further reduced by electroless deposition of $\mathrm{Au}$ inside the nanopore. In principle, the pore size can be as small as $1 \mathrm{~nm}$. The method of Au electroless deposition has been discussed previously in this chapter. For protein separation, the membrane selectivity of a mixture of lysozyme/bovine serum albumin is over 20 when the pore size of the $\mathrm{Au}$ nanotube membrane is $20 \mathrm{~nm}$ [10]. The selectivity of the mixture of $\beta$-lactoglobulin $\mathrm{A} /$ bovine serum albumin is over 15 [10].

\section{Fouling and Surface Modification}

For microfiltration, ultrafiltration and nanofiltration, fouling is a critical problem in losing mass transfer performance of the membrane over time $[16,17]$. For protein separation, the deposition of proteins within pores results in membrane fouling $[16,17]$. To avoid protein fouling, the surface of the Au nanotube membrane can be modified by chemisorption of a thiol-terminated poly(ethylene glycol). Thiol-terminated PEG can form a self-assembled monolayer (SAM) on the surface of gold and has been used for planar and curved surfaces to prevent adsorption of proteins [18]. The thiol terminated PEG is chemically bound to the Au surface and forms a hydrophilic layer that resists adsorption of proteins [18]. From comparisons of Au nanotube membranes with and without PEG modification, Au nanotube membranes with PEG modification show no blockage of lysozyme protein transport over 5 days, but show blockage in 8 hours without PEG modification [10].

Surface modified $\mathrm{Au}$ nanotube membranes have been used for chemical transport selectivity. Chemical interactions between permeate and membrane can be used to control the ion selectivity through the $\mathrm{Au}$ nanotube membranes. Surface of Au nanotube membranes can be chemically modified with thiol-terminated compounds with hydrophobic or hydrophilic groups. For example, surfaces of $\mathrm{Au}$ nanotubes chemical modified with hydrophilic $\mathrm{C} 2 \mathrm{H} 4 \mathrm{OH}-\mathrm{SH}$ show high transport of hydrophilic species, such as pyridine and hydrophobic surface modification $\left(\mathrm{Cl}_{6} \mathrm{H}_{33}-\mathrm{SH}\right)$ shows high transport of hydrophobic species, such as toluene [19].

\section{4. pH, Ionic Strength and Applied Potential Effects on Ion Separation}

Zydney and co-workers have shown that ionic strength and $\mathrm{pH}$ have profound effects on molecular separation by ultrafiltration [2024]. The electrostatic interactions between charged molecules and the charged membrane surface have profound effects on the transport of molecules through porous membranes [15, 2535]. Stroeve and co-workers demonstrated $\mathrm{pH}$-responsive transport of ions in $\mathrm{Au}$ nanotube membranes [2]. Self-assembled monolayers with weak acid or weak base functional groups can be chemically bound to the pore walls of $\mathrm{Au}$ nanotube membranes to form excess surface charge on the pore walls. The excess surface charge causes changes in the ion transport in the porous membrane. Moreover, the surface charges of these SAMs are $\mathrm{pH}$-responsive and thus the selectivity of ion transport is pH-responsive. Fig. 2 illustrates that carboxylic acid-functionalized SAMs on the pore walls of $\mathrm{Au}$ nanotube membranes cause $\mathrm{pH}$-responsive ion transport. Fig. 2a shows that when the $\mathrm{pH}$ is higher than the $\mathrm{pKa}$ of SAMs, the surface has negative charge. Transport of anions will be hindered by the negative surface charge on the pore walls, while the cation transport will not be hindered by the negative surface charge. Fig. $2 \mathrm{~b}$ shows that when the $\mathrm{pH}$ is lower than the pKa of the SAM, the surface becomes neutral. The flux of both of anions and cations will not be hindered electrostatically. Fig. 3 shows that $\mathrm{Au} / \mathrm{SAM}$ nanotube membranes have the highest transport of benzene sulfonate ions at low $\mathrm{pH}$. However, bare porous membranes and Au-coated nanotube membranes (without modification with SAMs) show much less response to $\mathrm{pH}$. Fig. 4 shows that the benzene sulfonate ion flux decreases as the ionic strength decreases. The lower the ionic strength, the more $\mathrm{pH}$-responsive the membrane is. The reduction of the flux of benzene sulfonate ions is directly related to the increase of the Debye length with decreasing ionic strength [3]. 
High $p H$

(negatively charged)

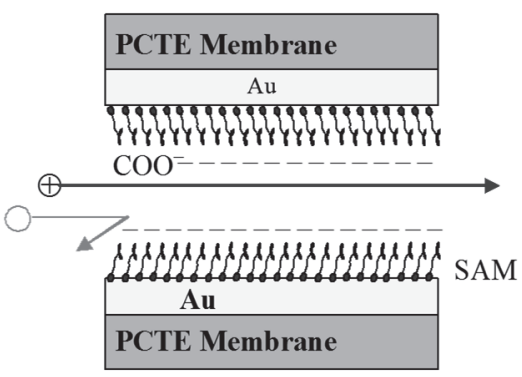

Low $p H$

(neutral)

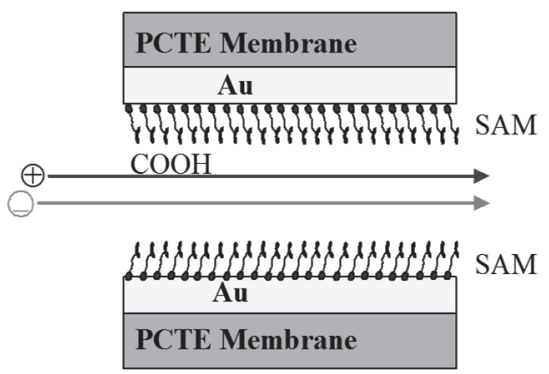

Fig. 2. (a) The pore surface is negatively charged due to weak acid SAM. Anions are rejected but cations can pass through the pore. (b) The surface is neutral. Both anions and cations can pass through pore.

The Debye length is a measure of the thickness of the electrical double layer [36]. When the ionic strength increases, the Debye length decreases and the benzene sulfonate ions can be transported more easily through the $\mathrm{Au} / \mathrm{SAM}$ nanotube membrane, because of reduced electrostatic repulsion along the periphery of the pore wall [3]. Additionally, since the $\mathrm{Au} / \mathrm{SAM}$ nanotube membrane is conductive, one can apply a potential directly to the surfaces of the pores. Fig. 11 demonstrates the effect of applied potentials on the flux of benzene sulfonate ion. The benzene sulfonate ion flux increases with increasing applied potential and with decreasing $\mathrm{pH}$.

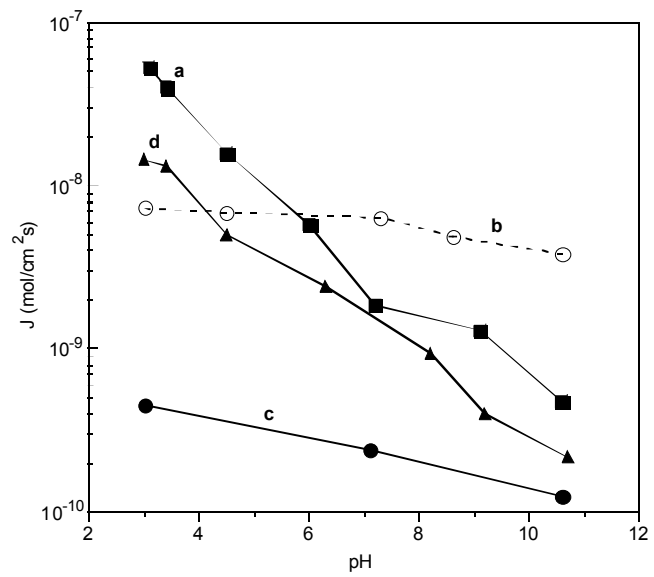

Fig. 3. Benzene sulfonate ion flux vs. pH. a, c, $\mathrm{d}$ are for surface modified membranes, $\mathrm{b}$ is for bare membrane. [2],

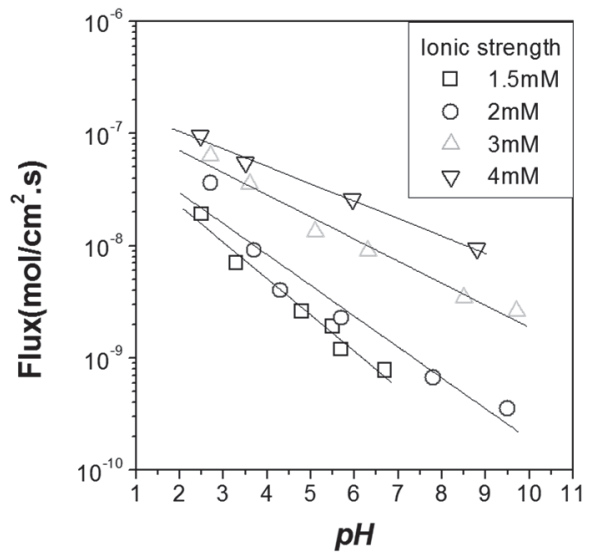

Fig. 4. Effect of ionic strength on benzene sulfonate ion transport through $\mathrm{Au} / \mathrm{SAM}$ nanotube membranes [3]

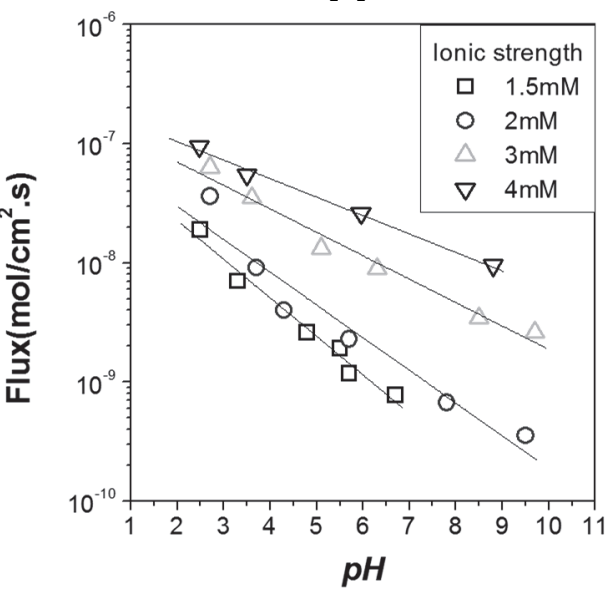

Fig. 5. Effect of applied potential of benzene sulfonate ion transport through $\mathrm{Au} / \mathrm{SAMs}$ nanotube membrane [3]. 
- Surface Charge and the Electrical Double Layer: pH and Ionic Strength Effects

The electrical double layer next to a charged surface represents the region containing the same amount of opposite charge as the excess charge on the surface. The physical thickness of electrical double layer can be calculated with the DebyeHückel approximation [36].

Electrical double layers are present at the pore surfaces and protein surfaces. The effects of electrostatic interactions between charged proteins and charged nanopore walls on the transport of the molecules through nanopores are very complicated. Some consider the double layer as an additional layer on the pore walls within the membrane, resulting in reduction of the effective pore size [37]. As the pore size of the membrane approaches the molecular scale, the electrical double layer can be critical in separation. For two proteins with similar molecular sizes, Stroeve and $\mathrm{Ku}$ obtained "On-Off" behavior of molecular transport by switching the electric double layer "On" or "Off" [1]. Fig. 6 shows schematically "On" and "Off" states of protein transport through an $\mathrm{Au} / \mathrm{SAM}$ nanotube membrane. Fig. 6a shows blockage of protein transport when the protein has an electrical double layer. In contrast to Fig. 6a, Fig. $6 \mathrm{~b}$ shows the protein transport through the $\mathrm{Au}$ nanoporous membrane when the protein doesn't have an electrical double layer.
The electrostatic repulsion between protein molecules and the nanopore walls can be switched "On" or "Off" by controlling the $\mathrm{pH}$ (Fig. 6). When the $\mathrm{pH}$ is exactly equal to the $\mathrm{pI}$ of protein $(\mathrm{pH}$ value at the isoelectric point), the protein has an overall neutral charge, no electrical double layer and then there is reduced electrostatic interactions between the protein and the pore surface, resulting in reduced hindered transport of protein through $\mathrm{Au} / \mathrm{SAM}$ nanotube membrane. When the $\mathrm{pH}$ deviates from the protein's $\mathrm{pI}$, the protein has positive or negative charge and an electrical double layer, and there are electrostatic interactions between the protein and the membrane, resulting in hindered transport of protein through the $\mathrm{Au} / \mathrm{SAM}$ nanotube membrane.

Bovine serum albumin (BSA) has no surface charge when the $\mathrm{pH}=4.7$ (pI of BSA $=4.7$ ), positive surface charge when the $\mathrm{pH}<$ 4.7 and negative surface charge when the $\mathrm{pH}>$ 4.7, as shown in Fig. 7. Similarly, bovine hemoglobin $(\mathrm{BHb})$ has no surface charge when the $\mathrm{pH}=4.7$ ( $\mathrm{pI}$ of $\mathrm{BHb}=7.0$ ), positive surface charge when the $\mathrm{pH}<7.0$, and negative surface charge when the $\mathrm{pH}>7.0$, as shown in Fig. 7. The positive or negative surface charge gives rise to electrical double layers on the surfaces of the proteins. For instance, bovine hemoglobin has the highest flux at its $\mathrm{pI}(\mathrm{pH}=7)$ through the $\mathrm{Au} / \mathrm{SAM}$ nanotube membrane, while bovine serum albumin has the highest flux at its $\mathrm{pI}(\mathrm{pH}=4.7)$ as shown in Fig. 8 [4].

\section{Protein with} charge

\section{Protein without charge}

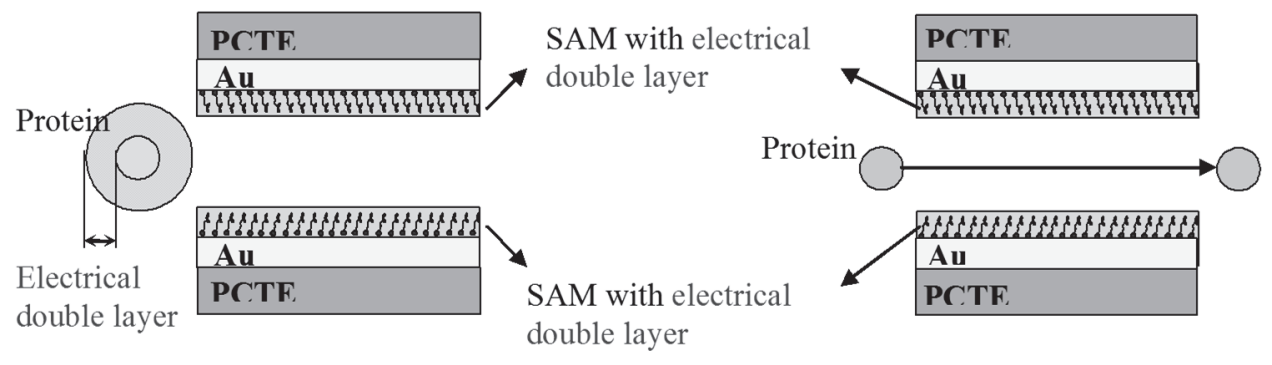

(a)

b)

Fig. 6. (a) Blockage of protein transport through $\mathrm{Au} / \mathrm{SAMs}$ nanoporous membrane when the protein is charged. (b) Protein transport through membrane when the protein doesn't have charge. 


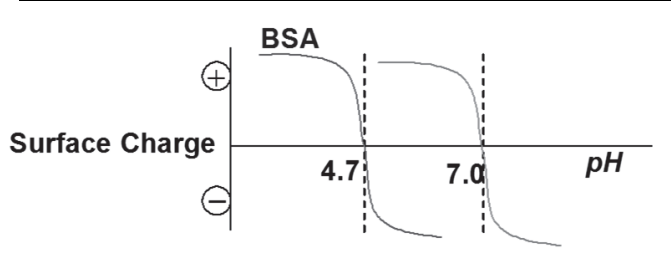

Fig. 7. Surface charges vs. $\mathrm{pH}$ of BSA and $\mathrm{BHb}$.

The thickness of the electrical double layer depends on the ionic strength: the lower the ionic strength, the larger the thickness of the electrical double layer [193]. Because of lower ionic strength $(10 \mathrm{mM})$, Fig. 8 shows a dramatic "On-Off" behavior of protein flux vs. $\mathrm{pH}$. Comparing the separation selectivity of a mixture of $\mathrm{BSA}$ and $\mathrm{BHb}$ at $\mathrm{pH}=4.7$ in solutions of either low ionic strength $(10 \mathrm{mM})$ or high ionic strength $(100 \mathrm{mM})$, the selectivity $(\alpha=67)$ in the low ionic strength is much higher than the selectivity $(\alpha=4.2)$ in the high ionic strength solution $[158,161]$. In a mixture with both $\mathrm{BSA}$ and $\mathrm{BHb}$ at $\mathrm{pH}=4.7$,

\section{Conical Nanoporous Membranes}

Another advantage of polymeric membrane is the capability of making conically shaped nanopores. Siwy and coworkers have formed conical nanoporous membranes by controlling a wet-etching process [38-39]. Martin and coworkers have fabricated conical nanoporous membranes by controlling a dry-etching process [40]. For the wet-etching process (Fig. 9), the irradiated polymer foil (etchable) is placed between two chambers: the left chamber has an etchant and right chamber has a stopping solution to neutralize the solution from the left chamber. The process starts to etch from left to right and stops shortly after the polymer foil has been broken through, which is indicated by a current measured with two electrodes. For the dry-etching process (Fig. 10), the nanoporous polymer membrane is etched by reactive ion etching (RIE) on one side to open up conical pores. The SEM image (Fig. 11) shows the side that has been RIE etched for $20 \mathrm{~min}$, leaving larger pores compared to the pores on un-etched side. Both SEM (Fig. 12) and TEM images (Fig. 13) show conical shapes of the Au nanotube.

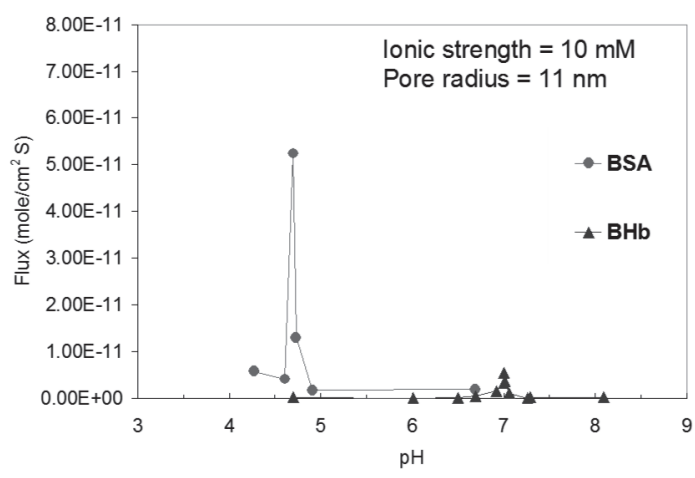

Fig. 8. Flux of BSA and BHb proteins through $\mathrm{Au} / \mathrm{SAMs}$ nanotube membrane in low ionic strength solution (ionic strength $=10 \mathrm{mM}$ ). [1]

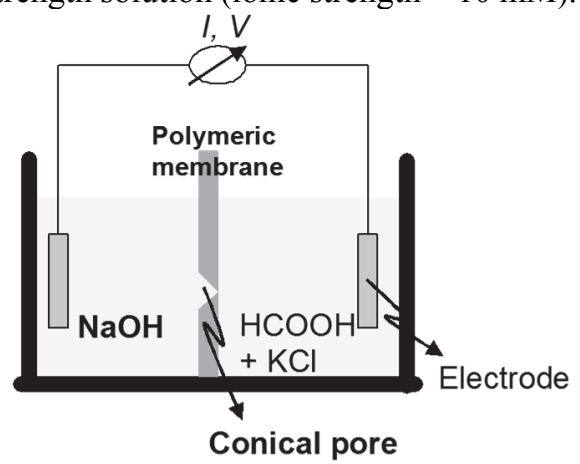

Fig. 9. Wet-etching process

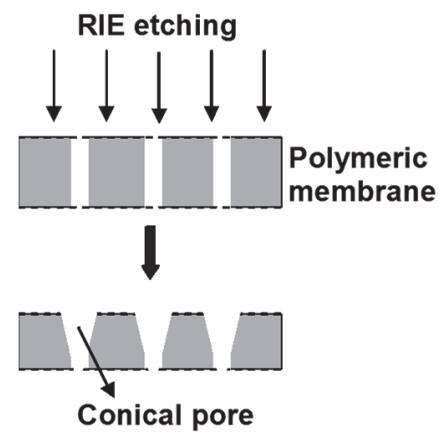

Fig. 10. Dry-etching to obtain conical pores.

The transport of ions through conical nanopore membranes has been studied and ion-current rectifier properties have been found [2847]. Due to the surface charge on the surface and the conical shape of the nanopores, the diffusion of ions is asymmetric. Fig. 14 shows two cases of ion transport: one case is for lower ionic strength at the small pore size side of the membrane, and the other case is for 
higher ionic strength is at the small pore size side of the membrane compared to the large pore size side. Because of the negatively charged surface, the electrical double layer and the distribution of the electric field inside the conical pores, the diffusion of $\mathrm{Cl}^{-}$in the first case (Fig. 14a) is faster than the second case (Fig. 14b). Diffusion of $\mathrm{K}^{+}$does not change significantly $[45,48]$.

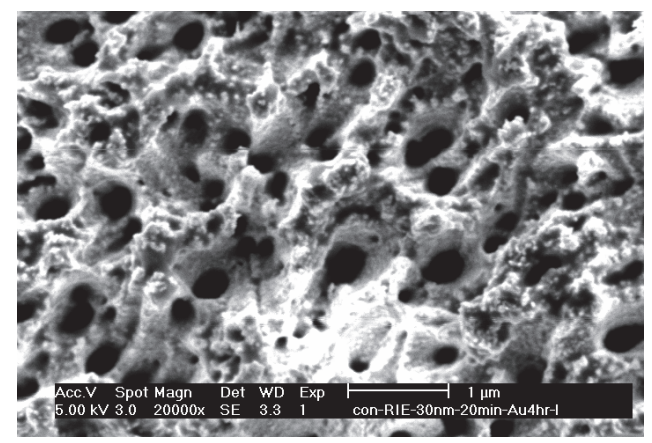

Fig. 11. Large pore size side of the membrane

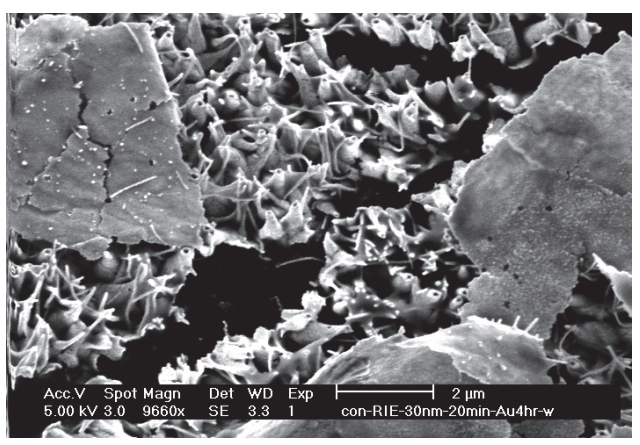

Fig. 12. SEM of conical Au nanotubes (in the center of the image). Large plates (left and right) are $\mathrm{Au}$ remnants from the small pore size side of the membrane.

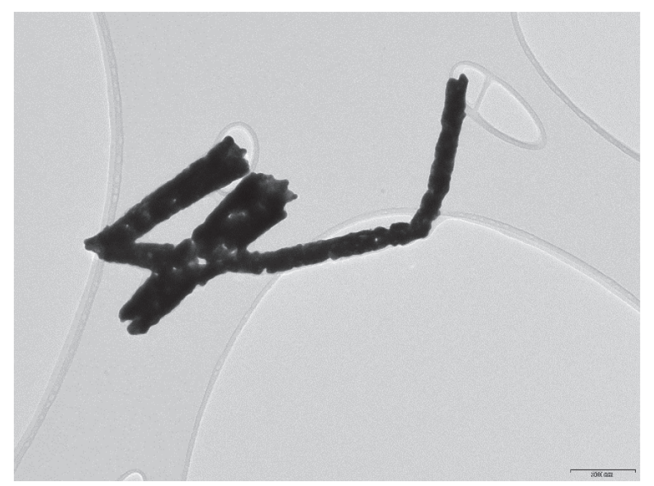

Fig. 13. TEM image of broken conical $\mathrm{Au}$ nanotube.

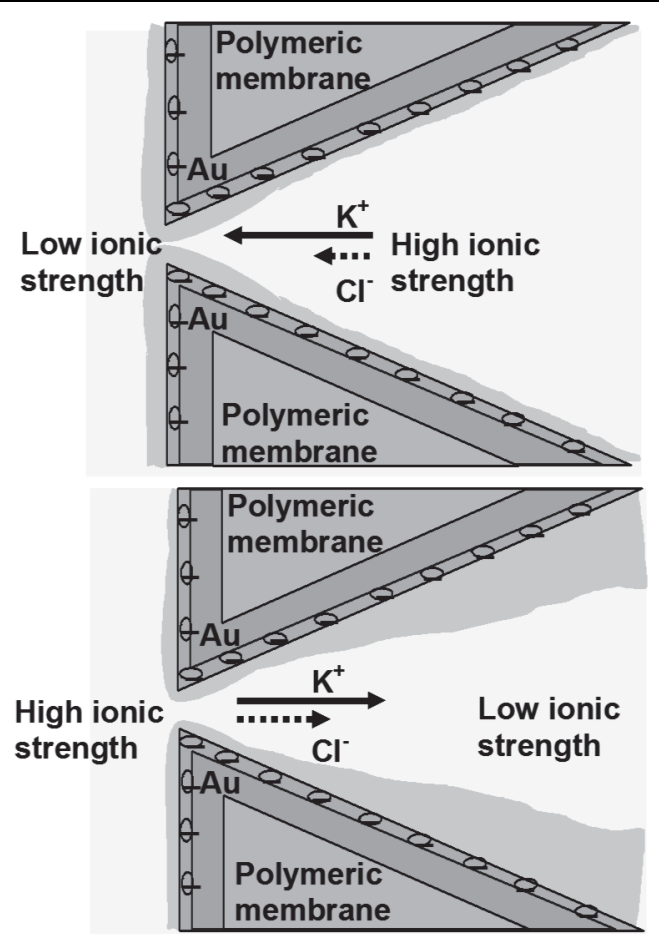

Fig. 14. Surface charge effect in conical nanopores. Darker blue region indicates the region of the electrical double layer.

\section{References}

1. J. R. Ku and P. Stroeve, Langmuir 20, 2030 (2004).

2. Z. Z. Hou, N. L. Abbott, and P. Stroeve, Langmuir 16, 2401 (2000).

3. K. Y. Chun and P. Stroeve, Langmuir 17, 5271 (2001).

4. K. Y. Chun and P. Stroeve, Langmuir 18, 4653 (2002).

5. P. Ugo, L. M. Moretto, G. A. Mazzocchin, P. Guerriero, and C. R. Martin, Electroanal. 10, 1168 (1998).

6. S. B. Lee, D. Mitchell, T. Nevanen, L. Trofin, H. Soderlund, and C. R. Martin, Abstracts of Papers of the American Chemical Society 223, U75 (2002).

7. M. S. Kang and C. R. Martin, Langmuir 17, 2753 (2001).

8. S. F. Yu, S. B. Lee, and C. R. Martin, Anal. Chem. 75, 1239 (2003).

9. K. B. Jirage, J. C. Hulteen, and C. R. Martin, Science 278, 655 (1997). 
10. S. F. Yu, S. B. Lee, M. Kang, and C. R. Martin, Nano Lett. 1, 495 (2001).

11. R. E. Gyurcsanyi, T. Vigassy, and E. Pretsch, Chem. Commun. 20, 2560 (2003).

12. M. A. Sanchez-Castillo, C. Couto, W. B.

Kim, and J. A. Dumesic, Angew. Chem. Int.

Edit. 43, 1140 (2004).

13. T. C. Kuo, D. M. Cannon, Y. N. Chen, J. J.

Tulock, M. A. Shannon, J. V. Sweedler, and P.

W. Bohn, Anal. Chem. 75, 1861 (2003).

14. T. C. Kuo, D. M. Cannon, M. A. Shannon, P. W. Bohn, and J. V. Sweedler, Sensor Actuat. A-Phys. 102, 223 (2003).

15. A. L. Zydney and N. S. Pujar, Colloid Surface A 138, 133 (1998).

16. L. J. Zeman and A. L. Zydney, in "Microfiltration and Ultrafiltration Principles and Applications." Marcel Dekker, Inc., New York, 1996, p. 397.

17. A. I. Schafer, A. G. Fane, and T. D. Waite, in "Nanofiltration-Principles and Applications." Elsevier Ltd., Oxford, 2005, p. 169.

18. T. B. Dubrovsky, Z. Hou, P. Stroeve, and N. L. Abbott, Analytical Chemistry 17, 327 (1999).

19. S. B. Lee and C. R. Martin, Chem. Mater. 13, 3236 (2001).

20. J. Romero and A. L. Zydney, Desalination 148, 159 (2002).

21. D. B. Burns and A. L. Zydney, J. Membrane Sci. 172, 39 (2000).

22. D. B. Burns and A. L. Zydney, Biotechnol. Bioeng. 64, 27 (1999).

23. D. B. Burns and A. L. Zydney, Abstracts of Papers of the American Chemical Society 216, U323 (1998).

24. B. Cheang and A. L. Zydney, Biotechnol. Bioeng. 83, 201 (2003).

25. M. F. Ebersold and A. L. Zydney, J. Membrane Sci. 243, 379 (2004).

26. M. F. Ebersold and A. L. Zydney, Biotechnol. Progr. 20, 543 (2004).

27. M. F. Ebersold and A. L. Zydney, Biotechnol. Bioeng. 85, 166 (2004).

25. N. S. Pujar and A. L. Zydney, J. Chromatogr. A 796, 229 (1998).

29. N. S. Pujar and A. L. Zydney, J. Colloid Interf. Sci. 192, 338 (1997).
30. N. S. Pujar and A. L. Zydney, Ind. Eng. Chem. Res. 33, 2473 (1994).

31. P. Ramirez, S. Mafe, A. Alcaraz, and J. Cervera, J. Phys. Chem. B 107, 13178 (2003). 32. S. Saksena and A. L. Zydney, Biotechnol. Bioeng. 43, 960 (1994).

33. S. Saksena and A. L. Zydney, J. Membrane Sci. 125, 93 (1997).

34. D. B. Burns and A. L. Zydney, AIChE Journal 47, 1101 (2001).

35. A. L. Zydney, Int. Dairy J. 8, 243 (1998).

36. P. C. Hiemenz and R. Rajagopalan, in "Principles of Colloid and Surface Chemistry." Marcel Dekker, Inc., New York, 1997, p. 499. 37. W. D. Munch, L. P. Zestar, and J. L. Anderson, J. Membrane Sci. 5, 77 (1979).

38. Z. Siwy and A. Fulinski, Phys. Rev. Lett. 89, 15 (2002).

39. Z. Siwy, P. Apel, D. Baur, D. D. Dobrev, Y. E. Korchev, R. Neumann, R. Spohr, C. Trautmann, and K. O.Voss, Surf. Sci. 532, 1061 (2003).

40. A. Fulinski, I. D. Kosinska, and Z. Siwy, Europhys. Lett. 67, 683 (2004).

41. Z. Siwy, P. Apel, D. Dobrev, R. Neumann, R. Spohr, C. Trautmann, and K. Voss, Nucl. Instrum. Meth. B 208, 143 (2003).

42. Z. Siwy, D. Dobrev, R. Neumann, C. Trautmann, and K. Voss, Appl. Phys. A-Mater. 76, 781 (2003).

43. Z. Siwy and A. Fulinski, Am. J. Phys. 72, 567 (2004).

44. Z. Siwy, E. Heins, C. C. Harrell, P. Kohli, and C. R. Martin, J. Am. Chem. Soc. 126, 10850 (2004).

45. Z. Siwy, I. D. Kosinska, A. Fulinski, and C. R. Martin, Phys. Rev. Lett. 94, 4 (2005).

43. Z. Siwy, Y. Gu, H. A. Spohr, D. Baur, A. Wolf-Reber, R. Spohr, P. Apel, and Y. E. Korchev, Europhys. Lett. 60, 349 (2002).

47. Z. Siwy, Y. C. Gu, H. A. Spohr, D. Baur, A. Wolf-Reber, R. Spohr, P. Apel, and Y. E. Korchev, Biophys. J. 82, 266A (2002).

48. Z. Siwy, L. Trofin, P. Kohli, L. A. Baker, C. Trautmann, and C. R. Martin, J. Am. Chem. Soc. 127,5000 (2005). 